\title{
Off-line testing of reluctance machines
}

\author{
Milutin G. Jovanović, Member, IEEE, and Robert E. Betz, Member, IEEE \\ Department of Electrical and Computer Engineering \\ University of Newcastle, NSW 2308, Australia
}

\begin{abstract}
Experimental techniques for determining the machine parameters and results demonstrating their performance on an axiallylaminated synchronous reluctance motor are presented. A new software implementation of the control algorithm for conducting an instantaneous flux-linkage test is developed. A low frequency AC test allowing better estimation accuracy compared to a standard $50-\mathrm{Hz}$ test is proposed. Effects of stator slotting on the quality of de torque test estimates are examined.
\end{abstract}

Keywords - Rotating machine testing, Inductance measurement, Parameter estimation.

\section{INTRODUCTION}

A conventional $d-q$ model in a rotor reference frame is commonly used for vector control of variable speed drives. The two crucial parameters that directly affect the machine/controller performance are the inductances in the $d q$ axes, $L_{d}$ and $L_{q}[1]$. Various running and locked rotor tests have been used for their estimation from measurements $[2,3]$. Most of the running methods [3] were performed on early line start synchronous reluctance (SyncRM) and large synchronous machines. Exceptions are the no-load test and the circle method.

The no-load test is often employed for predicting $L_{d}$ of cageless SyncRMs (Syncrels) [4-6]. It is also widely used for measuring mechanical and core losses $[4,5]$ this being impossible to achieve with locked rotor testing. While the $d$-axis test gives reasonably accurate inductance estimates, this is not the case with its $q$-axis counterpart due to pronounced sensitivity to stator resistance knowledge inaccuracies and iron loss influences.

The merit of the circle method [7] is the possibility of simultaneous identification of the machine inductances and stator resistance incorporating windage and iron losses. However, the test procedure itself and the experimental setup are complicated and the stator resistance is assumed operating point independent. It is interesting to note that

PE-008-EC-0-07-1998 A paper recommended and approved by the IEEE Electric Machinery Committee of the IEEE Power Engineering Society for publication in the IEEE Transactions on Energy Conversion. Manuscript submitted September 2, 1997; made available for printing July 2, 1998. many applications of this method have been reported in the Syncrel literature $[5,8,9]$, but none of them was for an axially-laminated design.

Unlike the running tests, the standstill tests $[2,3]$ require no special measuring equipment, have simple laboratory configuration and are more commonly used [2,10-12]. They include the DC bridge test, the AC test, the instantaneous flux-linkage test and the DC torque test. A significant advantage with respect to the rotating tests is the lower sensitivity to iron loss impact (except with the AC test) and therefore the higher accuracy.

A nice feature of the DC bridge test $[3,13,14]$ is that it is unaffected by eddy-currents losses and stator resistance variations. A limitation is the susceptibility to hysteresis iron loss effects and Wheatstone bridge unbalance related measurement errors [13]. It has been applied to permanent magnet motors [14]. It is also suitable for implementation on cage induction machines.

A conventional $\mathrm{AC}$ test $[2,3,8]$ is the standstill equivalent of the rotating no-load test. Because of its simplicity, it is traditionally used for measuring the inductances of both axially-laminated $[2,6]$ and simple salient-pole Syncrels [8]. The main sources of error with this test are the distortion of current waveforms resulting from $d$-axis saturation, and the presence of both stator and rotor core losses in a machine. It therefore offers satisfactory accuracy only under unsaturated operating conditions. Clearly, this test is not very useful for permanent magnet machine testing.

The flux-linkage test is undoubtedly the most versatile and has been successfully applied to switched reluctance $[10,11]$, permanent magnet and synchronous reluctance machines [2]. An advantage of the implementation in [10] is that the flux estimation accuracy is stator resistance independent. A serious drawback is the requirement for a bifilar motor winding. The main difficulty in implementing this test on a conventional machine is the temperature variation of $R$. A sensitivity analysis to stator resistance knowledge inaccuracies has been made in [12]. It was established that the minimum estimation errors could be achieved with larger voltage pulses and higher rate of change of current. However, the consequent eddy-current and skin effects were only mentioned, and were not quantified. A more advanced testing procedure overcoming all these practical difficulties has been proposed in [11].

The instantaneous flux test has several significant advantages that make it preferable to the $\mathrm{AC}$ and other tests. Firstly, an accurate measurement of the entire saturation curve $\lambda_{d q}$ vs $i_{d q}$ (one for each alignment position) is possi- 
ble from a single test. Secondly, the stator resistance can be estimated on-line [11]. Thirdly, the test does not suffer the core loss and skin effect related problems [2]. Finally; it is generally applicable to any machine. One deficiency is that it is more complicated than the $\mathrm{AC}$ test. In addition, the inductance estimation accuracy at very low currents is compromised by sensitivity issues [2].

The DC torque test allows the determination of $L_{d}-L_{q}$. While this test was primarily developed for predicting $L_{q}$ of cage SyncRM and classical synchronous machines from a knowledge of $L_{d}$ [3], it can be also used for Syncrel testing as will be shown in this paper. The DC nature of the test implies the absence of iron losses allowing accurate estimates. However, the major difficulty is the slotting torque ripple which deteriorate the $d-q$ model performance especially at higher current levels and with unskewed Syncrels. The test is therefore effective for estimating mainly the unsaturated inductances. Issues related to minimising slotting effects have been addressed in [3].

The objective of this paper is to present inductance measurement results for an axially-laminated Syncrel obtained from four different locked rotor tests: the standard $\mathrm{AC}$ test; the variable frequency $\mathrm{AC}$ test; the instantaneous flux-linkage test; and the DC torque test. In order to accurately determine $L_{d}$ and $L_{q}$ it was necessary to precisely locate the alignment positions of the rotor $d q$ axes with respect to the a-phase axis. A simple method used for this purpose is described next. In addition knowledge of the total machine-load inertia is required, since this is used in the angular velocity observer which is part of the vector controller for the Syncrel system [15]. This is estimated by conducting a step-torque test.

\section{TESTING PROCEDURES AND EQUIPMENT}

\section{A. Rotor Alignment Test}

The experimental configuration for determining the $d q$ axes alignment positions with the a-phase axis is shown in Fig. 1. The test is carried out in such a manner that the rotor is being moved until the readings of the ammeters in phases $b$ and $c$ become the same and exactly half of the third ammeter reading (in phase a). This balance of currents can be explained by the equal impedances of the phases $b$ and $c$ due to magnetic symmetry. Once the alignment position is reached, the shaft is clamped by means of a specially designed brake to prevent any movement of the rotor while logging the 10-bit absolute encoder reading displayed on the $\mathrm{PC}$ monitor (Fig. 2). This encoder measurement represents the a-axis position and it is used in the Syncrel controller for calculating the actual angular position of the rotor $d$-axis. The spatial positions of the other two phases can be located similarly. This allows one to properly determine which phase corresponds to which machine terminal so that the spatial sequence of the phases is ascertained.

The main merit of this test is the high sensitivity to rotor angle variations around alignment positions, excellent

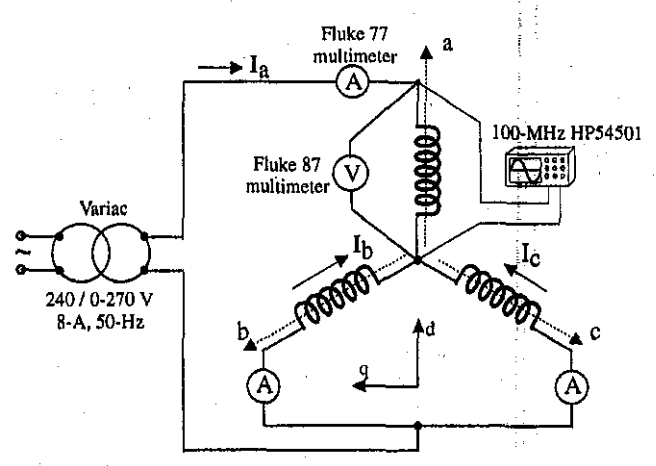

Fig. 1. Measurement of inductances and rotor alignment positions

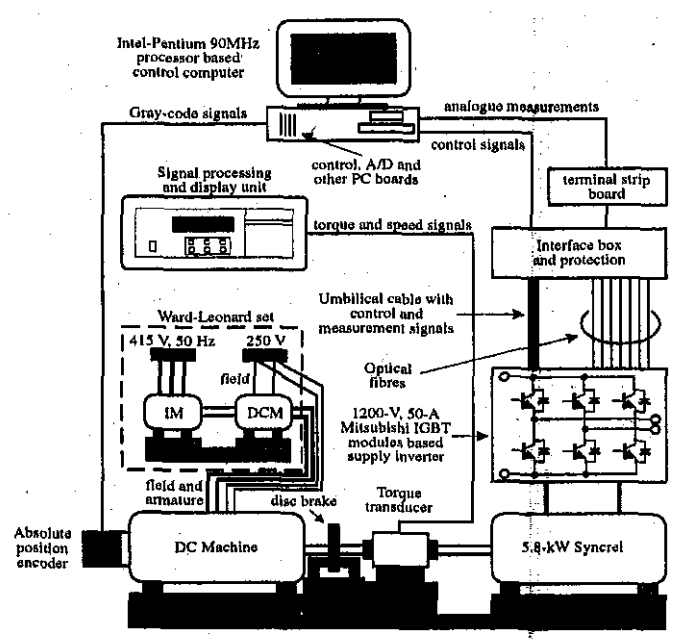

Fig. 2. Test Rig Layout

accuracy and simplicity.

\section{B. Step-Torque Test}

The testing procedure for predicting the total inertia constant $(J)$ of the Syncrel drive (Fig. 2) is fairly straightforward. The unloaded machine operated under torque control (no speed feedback) is started from standstill to a certain speed and the angular velocity waveform (software generated output of a D/A converter), estimated using an Euler approximation of the position derivative, is captured on a digital oscilloscope. The electromagnetic torque estimates from a standard saturated machine $d-q$ model are passed through a Butterworth digital filter to reduce noise effects and to eliminate inverter switching ripples. Considering that the filtered torque values $\left(T_{e m}\right)$ are approximately constant, the machine speed response is essentially linear and $J$ can be obtained from $J d \Omega / d t=T_{e m}$ where $d \Omega / d t$ is the slope of the recorded characteristic.

The step-torque test is simple to run and provides accurate estimates if fast and accurate torque control is possible. The estimated $J\left(0.23-\mathrm{kgm}^{2}\right)$ has allowed high performance of the Syncrel sensorless controller [15]. 


\section{AC Tests}

The $\mathrm{AC}$ test is carried out from $50-\mathrm{Hz}$ down to very low frequencies with the machine windings connected as in Fig. 1. This connection scheme is preferable to a single phase excitation [8] as the mutual flux effects are accounted for. The stator resistance $(R)$ used for the inductance estimation is measured by conducting a simple DC test immediately upon making the measurements to include potential temperature based changes. In this test a precise Fluke calibrator is employed as a current source and only the phase voltage measurements are needed. At $50-\mathrm{Hz}$, one can alternatively use the $\mathrm{AC}$ values of $R$ (in this case a digital wattmeter is connected across the phase-a terminals to measure the power input) but in this interpretation $R$ represents the total losses of the machine and is therefore overestimated due to the iron losses.

The equipment used for the standard $50-\mathrm{Hz}$ test is presented in Fig. 1. The approximate value of the leakage inductance $(4.17-\mathrm{mH})$ is measured using a HP4332A LCR meter when the rotor is removed. An iron loss (realistic) machine model [4] is applied to generate the best possible estimates of the unsaturated $L_{d}$ and $L_{q}$.

The estimation accuracy can be improved by reducing iron losses and skin effects. This is achieved by running the test at low frequency and voltage levels. The machine is fed from a sinusoidal variable voltage-frequency supply consisting of a HP $3312 \mathrm{~A}$ function generator and a $2.5-\mathrm{A}$ power amplifier (not shown in Fig. 1). The voltage and current waveforms of phase-a are recorded on a digital oscilloscope which performs the data processing required for accurate measurement of frequency, voltage and current. The inductances are then calculated using the ideal model equations neglecting core losses.

\section{Instantaneous Flux Linkage Test}

The test essentially follows the direct method published in [11] but the implementation is quite different. The experimental setup is shown in Fig. 2. The machine is supplied with only two inverter legs, the stator winding arrangement being unchanged (Fig. 1). The control software, written in ' $\mathrm{C}$ ', was implemented using a PC processor with a custom made I/O board serving as an interface to the $\mathrm{CPU}$ bus for the encoder and inverter hardware. A description of the design and functionality of this board can be found in [15].

The voltage and current of the phase-a are measured by precise potential dividers and current shunts respectively. The measurement data is sampled and transferred to a PC memory by a 12-bit A/D board with interrupt capabilities [16]. This board is also programmed for $\mathrm{D} / \mathrm{A}$ conversions to allow the integrated flux waveform to be displayed on a digital oscilloscope.

Firing of the inverter power devices is carried out in a slightly unusual manner. A DC link voltage is firstly adjusted to the lowest possible value required to drive the desired current. By doing this, the rate of change of cur- rent, and hence the eddy current losses, are minimised. The voltage pulse is applied to the machine by turning the top transistor of a leg on (the bottom one of the other leg is on by default) and the current is allowed to increase to a preset level. Once this is attained, the voltage is turned off (all devices are disabled) and the current decays back to zero through the freewheeling diodes and the regeneration circuit. The transistors are enabled again but with a certain delay and the process is repeated.

The purpose of introducing a firing delay is to ensure enough time for the current to go to zero before turning the devices on. An additional benefit is the longer zero flux interval which makes it easier for the user to see whether the flux waveform lies in the zero axis. If it does not, the $R$ value is changed on-line via a PC terminal interface until any offset is eliminated. Consequently good estimation accuracy of both $R$ and the machine flux can be obtained.

Samples of the phase voltage and current are used for the flux numerical calculation. A trapezoidal approximation is applied for the back-emf integration :-

$$
\lambda_{n}=\sum_{k=1}^{n}\left(u_{k}-R \frac{i_{k+1}+i_{k-1}}{2}\right)\left(t_{k+1}-t_{k-1}\right)
$$

As the board is multiplexed the sampling is not simultaneous and thus, the current sample $i_{k-1}$ is taken first followed by the voltage sample $u_{k}$. This means that the flux estimates update rate is half the sampling frequency $(\approx 8$ $\mathrm{kHz}$ ) i.e. $t_{k+1}-t_{k-1} \approx 250 \mu \mathrm{s}$. The sampling intervals are precisely measured by means of a PC timer. In order to reduce the integration error, the integrator is reset at the beginning of each new cycle. The current samples and the corresponding flux estimates from the $d q$ tests are saved in data files for postprocessing using Matlab ${ }^{\circledR}$ to generate the $L_{d q}$ vs $i_{d q}$ curves.

\section{E. DC Torque Test}

The circuit diagram is the same as for the previous two tests. The difference is that the variable transformer (variac) in Fig. 1 is replaced by a 72-V, 10-A, dual DC power supply. The terminal current and torque measurements are made with the rotor locked in various $d$-axis positions relative to the phase-a $(\theta)$. Note that $\theta$ is actually the current angle as the stator mmf is aligned with the a-axis. The $L_{d}-L_{q}$ estimates for a 4-pole Syncrel are easily found using $\tau=1.5\left(L_{d}-L_{q}\right) I_{a}^{2} \sin 2 \theta$. The maximum relative estimation error for an unsaturated machine can be expressed as :-

$$
\frac{\Delta\left(L_{d}-L_{q}\right)}{L_{d}-L_{q}}=\frac{\Delta \tau}{\tau}+2 \frac{\Delta I_{a}}{I_{a}}+2\left|\frac{\cos 2 \theta}{\sin 2 \theta}\right| \Delta \theta
$$

where $\Delta \tau, \Delta I_{a}$ and $\Delta \theta$ are the absolute accuracies of the measuring equipment. Clearly, the best results are obtained at higher test currents and the optimal torque current angle. 


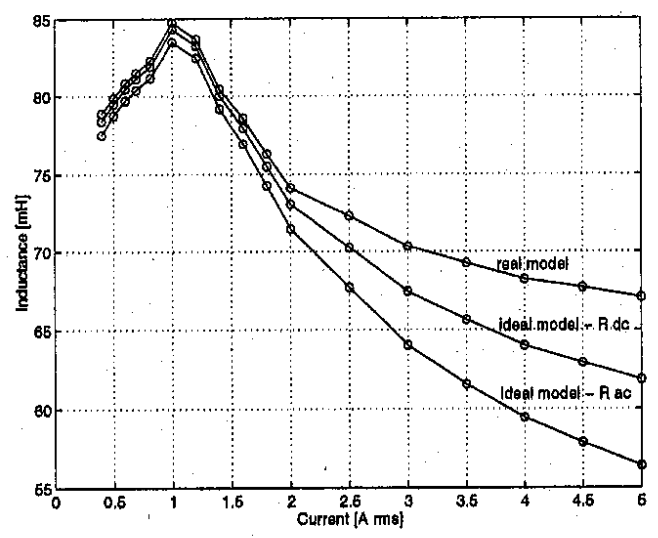

Fig. 3. $L_{d}$ estimates from $50-\mathrm{Hz} \mathrm{AC}$ test

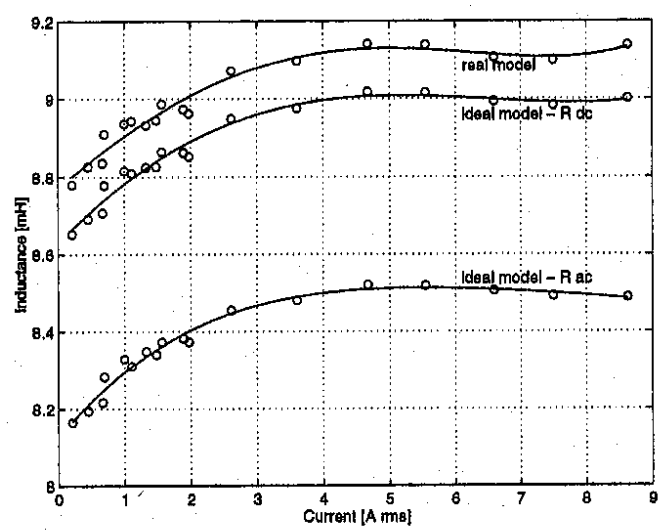

Fig. 4. Estimated $L_{q}$ from $50-\mathrm{Hz}_{z} \mathrm{AC}$ test

\section{MEASUREMENT RESULTS}

The plots for the unsaturated $L_{d}$ of the Syncrel prototype (see Appendix) generated from the $50-\mathrm{Hz} \mathrm{AC}$ test measurements are shown in Fig. 3. The test is conducted at smaller currents to avoid saturation and minimise iron losses. Despite this, the computed $L_{d}$ values decrease substantially with an increase in current, particularly if derived from the ideal model. The poorest results are obtained by using $R_{a c}$ estimates. This is expected considering that the skin effects are dominated by the iron loss influences and deviations of $R_{a c}$ from the measured $R_{d c}$ are consequently large. At very low currents, on the other hand, there is a reasonably good agreement between the curves as the core losses are insignificant. The $L_{d}$ fall in this current range caused by a low magnetic permeability of the stator and rotor iron is normally ignored and $L_{d}$ is approximated by an average estimated value (Table I).

Most of the previous observations can be extended to the $q$-axis test results in Fig. 4. A key difference however is that, unlike the $d$-axis test situation, the inductance characteristics are fairly flat at higher currents as the flux levels and iron losses are low. An average estimate corresponding to the realistic model curve is given in Table I.

By carrying out measurements at very low frequencies

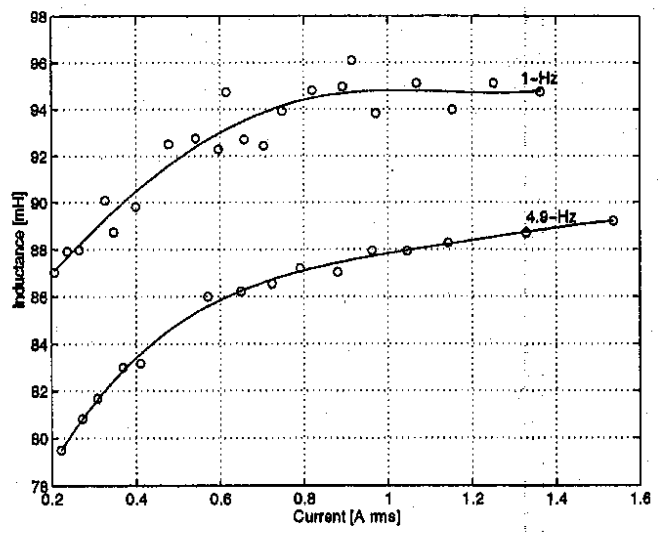

Fig. 5. Low frequency d-axis $A C$ test results using ideal model

and currents, the $d$-axis test accuracy is considerably improved as illustrated in Fig. 5. It can be seen that $L_{d}$ estimates become approximately constant as the current increases and are larger than at $50-\mathrm{Hz}$ (Fig. 3). Nevertheless, iron losses start to manifest themselves with a rise of frequency resulting in the ideal model predictions being underestimated as in the previous cases.

The $q$-axis low frequency test is performed at somewhat higher frequency levels $(5-\mathrm{Hz}$ and $20-\mathrm{Hz})$ so that $X_{q}=\omega L_{q}$ be comparable to $R$. This reduces the numerical sensitivity of the ideal model inductance expression to measurement inaccuracies. The fluctuating $L_{q}$ estimates (it was considered meaningless to present these graphically) are averaged and the most accurate value $(\mathrm{at} 5-\mathrm{Hz})$ is shown in Table $\mathrm{I}$. Variations from this value are less than $5 \%$ at $20-\mathrm{Hz}(0.46-$ $\mathrm{mH}$ ) increasing to about $6.5 \%$ at $50-\mathrm{Hz}$ (Table I). These figures indicate virtually negligible iron loss influences over the entire frequency range.

The $d$-axis saturation characteristic (dashed line) and a hysteresis loop predicted using the instantaneous fluxlinkage test are presented in Fig. 6. These are obtained from the experimental flux waveform consisting of a number of cycles each producing one ascending (when the current rises up to 25-A) and one descending flux curve (when the current goes back to zero). The measurements for all cycles are averaged to help eliminate noise effects. The minimum fundamental frequency achieved was approximately $9-\mathrm{Hz}$.

One can observe that the flux decays to zero from some initial value even though there is no current through the windings (slight deviations from zero result from the measurement quantization). It was found that this flux falling was in fact a reflection of the actual phase voltage waveform. Namely, instead of the expected almost instantaneous drop, the voltage was decreasing to zero with a relatively large time constant. This phenomenon may be due to link capacitor effects because of the DC link floating with respect to earth. In order to verify the test effectiveness, it was firstly tried on both a single air-core inductor and three identical star connected air-core inductors whose parameters were previously measured using a precise LCR 


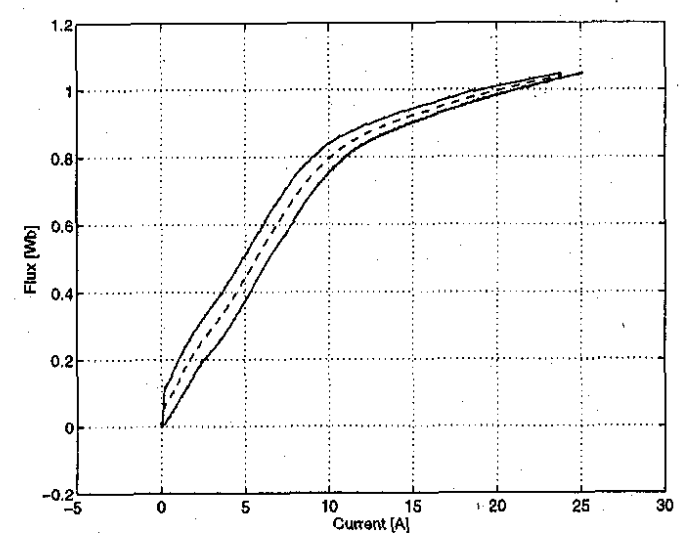

Fig. 6. Hysteresis loop and magnetizing curve from d-axis flux test

instrument. The estimated inductance was shown to be fairly accurate in both cases despite the fact that similar flux behaviour was experienced at zero current. Another confirmation of the quality of flux-test $L_{d q}$ estimates was their successful use in a high performance sensorless controller for the Syncrel [15].

The existence of the flux offset introduces stator resistance estimation errors, which together with the inherent sensitivity of $L_{d q}=\lambda_{d q} / i_{d q}$ to $i_{d q}$ makes the test unreliable at low currents [2]. This is however not a serious limitation as $L_{d}$ is usually assumed constant in this current range as mentioned earlier. The saturated portion of the average $L_{d}$ vs $i_{d}$ characteristic $\left(i_{d} \geq 4.9-\mathrm{A}\right)$ can be accurately represented by the following polynomial :-

$$
\begin{gathered}
L_{d}=1.489 \cdot 10^{-5} i_{d}^{6}-1.2865 \cdot 10^{-3} i_{d}^{5}+4.3288 \cdot 10^{-2} i_{d}^{4} \\
-0.7049 i_{d}^{3}+5.5906 i_{d}^{2}-21.565 i_{d}+121.77
\end{gathered}
$$

The value at $4.9-\mathrm{A}$ was adopted for the unsaturated $L_{d}$ (Table I).

The results of the $q$-axis flux test are plotted in Fig. 7 . Since the $q$-axis time constant is much less than in the $d$-axis, the minimum operating frequency accomplished is higher $(23-\mathrm{Hz})$ than with the $d$-axis test. The pronounced sensitivity effects and noisy measurements result in small ripples in the rising flux waveform. Note also that the saturation characteristic is approximately linear (as one would expect), and the corresponding $L_{q}$ value was only marginally different from that estimated by the low frequency AC test (see Table I).

Fig. 8 demonstrates the stator slotting influence on the machine and DC torque test performance. The fundamental torque components varying with $\sin 2 \theta$ (dashed lines) are determined by a polynomial fit of the measurement data. There are obviously two ripples (one for each slot/teeth) in the measured torque characteristics per $45^{\circ}$ as the 4-pole Syncrel stator has 36 slots. It is interesting that these ripples occur only at the current angles when the $\mathrm{mmf}$ is predominantly in the $d$-axis. The possible explanation for this phenomenon is the increased sensitivity of the $d$-axis flux to air-gap length variations since its path

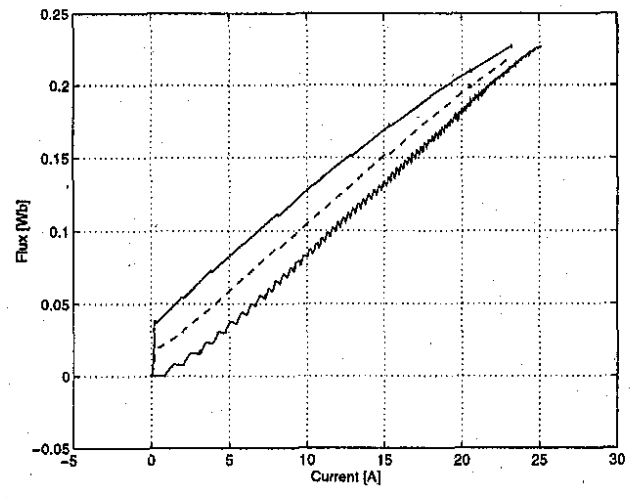

Fig. 7. Flux waveforms from q-axis flux-linkage test

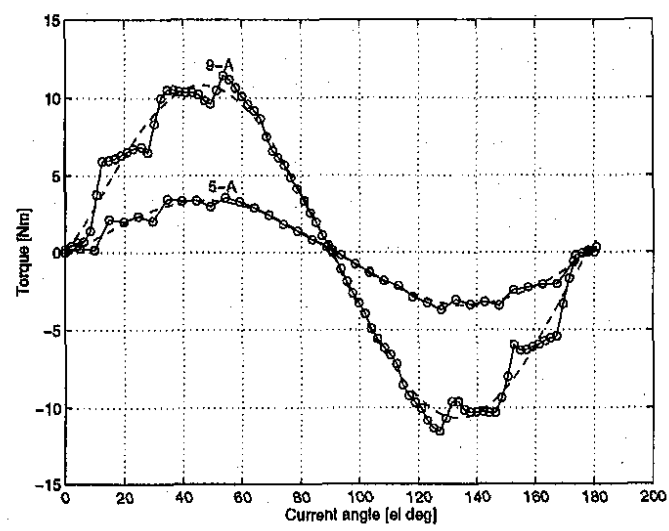

Fig. 8. Syncrel torque characteristics obtained by dc torque test

is mainly through laminations. On the other hand, insulation layers are dominant in the $q$-axis flux path and the slotting effects are insignificant. These practical influences adversely affect the test accuracy making it useful essentially for estimating the unsaturated inductances of axially-laminated Syncrels. Unfortunately, due to limitations of the laboratory supply, the full saturation curve of the machine could not be measured to support this conjecture. The results presented in Table I have been generated from the torque measurements at $6-\mathrm{A}$ and $45^{\circ}$ current angle.

\section{CONCLUSIONS}

The major contribution of the paper is the consideration and performance evaluation of various practical methods for estimating the parameters of switched reluctance machines and Syncrels. The measuring equipment, testTABLE I

Test Syncrel Unsaturated Inductances

\begin{tabular}{|c|c|c|c|c|}
\hline \multirow{2}{*}{$\begin{array}{c}\text { Machine } \\
\text { parameter }\end{array}$} & \multicolumn{4}{|c|}{ Test type } \\
\cline { 2 - 5 } & AC $(\mathbf{f}=50-\mathrm{Hz})$ & AC (low $\mathrm{f})$ & Flux & DC torque \\
\hline $\bar{L}_{d}$ & 82 & 94.7 & 88.9 & - \\
\hline$L_{q}$ & 9.11 & 9.75 & 9.8 & - \\
\hline$L_{d}-L_{q}$ & 72.89 & 84.95 & 79.1 & 88.65 \\
\hline
\end{tabular}


TABLE II

Test Syncrel Parameters

\begin{tabular}{||c||c||}
\hline \hline Power & $5.8-\mathrm{kW}$ \\
Current (rms) & $14.3-\mathrm{A}$ \\
Current angle & $60^{\circ}$ \\
Speed & $1500-\mathrm{rpm}$ \\
\hline \hline Air-gap & $0.48-\mathrm{mm}$ \\
Rotor diameter/length & $126 / 175-\mathrm{mm}$ \\
Insulator thickness & $0.38-\mathrm{mm}$ \\
Lamination thickness & $0.35-\mathrm{mm}$ \\
Lamin.-insul. layers & 43 \\
Pole arc/piece & $120^{\circ}$ elec/brass \\
\hline
\end{tabular}

ing procedures and experimental results for five different tests applied to an axially-laminated Syncrel have been presented.

A novel fully software implementation of the versatile flux estimation algorithm applicable to any brushless machine has been developed. This implementation is based on a Pentium PC processor and off-the-shelf digital hardware. It has the advantage of allowing highly accurate inductance estimates using an existing variable speed drive experimental system.

An original configuration for conducting the AC test at very low frequencies has been proposed and the accuracy of the $50-\mathrm{Hz}$ test improved employing a digital oscilloscope. Despite the inherent sensitivity to measurement quantization, a good correlation with the flux-test results has been shown especially in the $q$-axis test case.

Satisfactory estimates of unsaturated inductances have been also obtained by both the conventional AC and DC torque tests. The first suffered from iron loss effects at higher currents giving useless predictions for $L_{d}$. The problem with the second was slotting torque ripple related inaccuracy.

Overall, the instantaneous flux linkage test procedure appears to give the best results for the $d$ and $q$ axis inductances, this being especially true with respect to the saturation characteristic of the $d$ axis.

The subject of the future work on Syncrel parameter identification is the development of a no-load running test. A LabVIEW ${ }^{\circledR}$ data acquisition equipment has been recently installed in the laboratory for this purpose. On-line estimation techniques will be also investigated.

\section{APPENDIX}

\section{TEST MACHINE}

A 4-pole Syncrel (Table II) has a commercial 7.5-kW, 415- $\mathrm{V}$ induction machine stator of DF132M frame size and a cageless axially-laminated rotor similar to that described in [2]. Both the rotor and the supply inverter have been built in the department workshop.

\section{REFERENCES}

[1] A.E.Fitzgerald, C.Kingsley, and S.D.Umans, Electric machinery. McGraw Hill, 1990.
[2] W.L.Soong, Design and Modelling of Axially-Laminated Interior Permanent Magnet Motor Drives for Field-Weakening Applications. $\mathrm{PhD}$ thesis, Department of Electronics and Electrical Engineering, University of Glasgow, September 1993.

[3] E.A.Klingshirn, "Dc standstill torque used to measure $l_{q}$ of reluctance and synchronous machines," IEEE Transactions on Power Apparatus and Systems, vol. PAS-97, no. 5, pp. 1862$1869,1978$.

[4] L.Xu, X.Xu, T.A.Lipo, and D.W.Novotny, "Vector control of a synchronous reluctance motor including saturation and iron loss," IEEE Transactions on Industry Applications, vol. 27, no. 5, pp. 977-985, 1991.

[5] T.Fukao, A.Chiba, and M.Matsui, "Test results on a super-highspeed amorphous-iron reluctance motor," IEEE Transactions on Industry Applications, vol. 25, no. 1, pp. 119-125, 1989.

[6] I.Boldea, Z.X.Fu, and S.A.Nasar, "Performance evaluation of axially-laminated anisotropic (ala) rotor reluctance synchronous motors," IEEE Transactions on Industry Applications, vol. 30, no, 4, pp. 977-985, 1994.

[7] A.A.Fock and P.M.Hart, "New method for measuring $x_{d}$ and $\mathrm{x}_{q}$ based on the $\mathrm{p}-\mathrm{q}$ diagram of the lossy salient-pole machine," IEE Proceedings, Pt.B, vol. 131, pp. 259-262, November 1984.

[8] A.Chiba, F.Nakamura, T.Fukao, and M.A.Rahman, "Inductances of cageless reluctance-synchronous machines having nonsinusoidal space distributions," IEEE Transactions on Industry Applications, vol. 27, no. 1, pp. 44-51, 1991.

[9] P.Y.P.Wung and H.B.Puttgen, "Synchronous reluctance motor operating point dependent parameter determination," IEEE Transactions on Industry Applications, vol. 28, no. 2, pp. 358$363,1992$.

[10] H.C.Lovatt and J.M.Stephenson, "Measurement of magnetic characteristics of switched-reluctance motors," Proc. ICEM, pp. 465-469, 1992.

[11] C.Cossar and T.J.E.Miller, "Electromagnetic testing of switched reluctance motors," Proc. ICEM, pp, 470-474; 1992.

[12] P.W.Lee and C.Pollock, "Flux linkage estimation in electrical machines," Proc. ICEM, pp. 463-467, France, 1994.

[13] R.W.Menzies, R.M.Mathur, and H.W.Lee, "Theory and operation of reluctance motors with magnetically anisotropic rotors ii - synchronous performance," IEEE Trans., vol. PAS-91, pp. 4245,1972 .

[14] T.J.E.Miller, "Methods for testing permanent magnet polyphase ac motors," Proc. IEEE-IAS Annual Meeting, pp. 494-499, 1981.

[15] M.G.Jovanovic, R.E.Betz, and D.Platt, "Sensorless vector controller for a synchronous reluctance motor," IEEE-IAS Annual Meeting, pp. 122-129, San Diego, California, October 1996.

[16] User Manual for DT2821 series. Data Translation, 1987.

Milutin G. Jovanović received the Dipl.Eng and M.E.E. degrees from University of Belgrade, Belgrade, Yugoslavia, in 1987 and 1991 respectively, and the Ph.D. degree from the University of Newcastle, Newcastle, Australia, in 1997.

$\mathrm{He}$ is currently a.Lecturer in the School of Electrical Engineering, Electronics and Physics, Liverpool John Moores University, Liverpool, U.K. His major interests lie in the areas of electrical machines and drives, industrial electronics and power systems.

$\mathrm{Dr}$. Jovanović is a member of the Industrial Drives Committee of the IEEE Industry Applications Society.

Robert E. Betz (M'g2) received the B.E., M.E. and Ph.D. degrees from the University of Newcastle, Newcastle, Australia in 1979, 1982 and 1984 respectively.

He is currently a Senior Lecturer in the Department of Electrical and Computer Engineering, University of Newcastle, His major interests are electrical machine drives, real-time operating systems, and industrial electronics.

Dr. Betz is a member of the Industrial Drives Committee of the IEEE Industry Applications Society. 